\title{
Differences Between Surviving and Non-surviving Venous Thromboembolism COVID-19 Patients: A Systematic Review
}

\section{Mauricio Castillo-Perez}

TecSalud: Instituto Tecnologico y de Estudios Superiores de Monterrey Escuela de Medicina Ignacio A Santos

\section{Carlos Jerjes-Sanchez ( $\square$ jerjes@prodigy.net.mx )}

Centro de Investigacion Biomedica del Hospital Zambrano Hellion, TecSalud. Instituto de Cardiologia y Medicina Vascular, TecSalud https://orcid.org/0000-0003-3222-7405

\section{Alejandra Castro-Varela}

TecSalud: Instituto Tecnologico y de Estudios Superiores de Monterrey Escuela de Medicina Ignacio A Santos

\section{Jose Gildardo Paredes-Vazquez}

Hospital Zambrano Hellion Instituto de Cardiologia y Medicina Vascular

\section{Eduardo Vazquez-Garza}

TecSalud: Instituto Tecnologico y de Estudios Superiores de Monterrey Escuela de Medicina Ignacio A Santos

\section{Ray Erick Ramos-Cazares}

TecSalud: Instituto Tecnologico y de Estudios Superiores de Monterrey Escuela de Medicina Ignacio A Santos

\section{Jose Alfredo Salinas-Casanova}

TecSalud: Instituto Tecnologico y de Estudios Superiores de Monterrey Escuela de Medicina Ignacio A Santos

\section{Abigail Montserrat Molina-Rodriguez}

TecSalud: Instituto Tecnologico y de Estudios Superiores de Monterrey Escuela de Medicina Ignacio A Santos

\section{Arturo Adrian Martinez-lbarra}

TecSalud: Instituto Tecnologico y de Estudios Superiores de Monterrey Escuela de Medicina Ignacio A Santos

\section{Mario Alejandro Fabiani}

TecSalud: Instituto Tecnologico y de Estudios Superiores de Monterrey Escuela de Medicina Ignacio A Santos

\section{Yoezer Z Flores-Sayavedra}


TecSalud: Instituto Tecnologico y de Estudios Superiores de Monterrey Escuela de Medicina Ignacio A Santos

\section{Jaime Alberto Guajardo-Lozano}

TecSalud: Instituto Tecnologico y de Estudios Superiores de Monterrey Escuela de Medicina Ignacio A Santos

\section{Hector Lopez-de la Garza}

TecSalud: Instituto Tecnologico y de Estudios Superiores de Monterrey Escuela de Medicina Ignacio A Santos

\section{Hector Betancourt-del Campo}

TecSalud: Instituto Tecnologico y de Estudios Superiores de Monterrey Escuela de Medicina Ignacio A Santos

\section{Daniela Martinez-Magallanes}

TecSalud: Instituto Tecnologico y de Estudios Superiores de Monterrey Escuela de Medicina Ignacio A Santos

\section{Jathniel Panneflek}

TecSalud: Instituto Tecnologico y de Estudios Superiores de Monterrey Escuela de Medicina Ignacio A Santos

\section{Research}

Keywords: SARS-CoV-2, COVID-19, venous thromboembolism, pulmonary embolism, deep vein thrombosis, thrombolysis, anticoagulation

Posted Date: May 13th, 2021

DOl: https://doi.org/10.21203/rs.3.rs-509598/v1

License: (c) (1) This work is licensed under a Creative Commons Attribution 4.0 International License. Read Full License

Version of Record: A version of this preprint was published at Thrombosis Journal on December 1st, 2021. See the published version at https://doi.org/10.1186/s12959-021-00346-y. 


\section{Abstract}

Background: Systematic reviews of venous thromboembolism COVID-19 patients focus on the incidence, primary and secondary venous thromboembolism prevention, bleeding complications, and the association of D-dimer with mortality. We analyzed therapeutic approaches, outcomes, clinical presentation, risk stratification, and patient characteristics that survived and did not survive.

Methods: We searched for systematic reviews, cohorts, case series, case reports, editor letters, and venous thromboembolism COVID-19 patients' abstracts following PRISMA and PROSPERO statements. The objective was to assess therapeutic trends and clinical outcomes of venous thromboembolism COVID-19 patients. Inclusion: COVID-19 patients with venous thromboembolism confirmed by an imaging method (venous doppler ultrasound, ventilation-perfusion lung scan, computed tomography pulmonary angiogram, pulmonary angiography). We assessed the original Pulmonary Embolism Severity Index in two groups, survivors and those who died. We defined major bleedings according to the International Society of Thrombosis and Haemostasis criteria.

Results: We performed a systematic review from August 9 to August 30, 2020. We collected 1,535 papers from PubMed, Scopus, Web of Science, Wiley, and Opengrey. We extracted data from 89 studies. Unfractionated and low-molecular-weight heparin drove parenteral anticoagulation. The Food and Drug Administration-approved alteplase regimen guided the advanced treatment in both groups. The mortality was high (21.6\%), with a low incidence of bleeding complications in those who survived: Pulmonary Embolism Severity Index class II and III identified patients who lived. Patients who experienced venous thromboembolism events at home were more likely to live than in-hospital events. Patients who died had a higher $\mathrm{D}$ dimer expression and right ventricular dysfunction.

Conclusions: We determined a high mortality incidence of pulmonary embolism (21.6\%) related to hypertension, an increased inflammatory response, prothrombotic state, severe COVID-19, massive pulmonary embolism, intensive care unit admission, low venous thromboembolism prophylaxis, and bleeding complications. The original Pulmonary Embolism Severity Index could be helpful in the risk stratification. Overlapping severe COVID-19 pneumonia and pulmonary embolism is a challenge.

\section{Background}

The rapidly evolving coronavirus disease 2019 (COVID-19) global pandemic is one of the most significant public health challenges since the Spanish flu pandemic over 100 years ago (1). COVID-19, caused by the severe acute respiratory syndrome coronavirus 2 (SARS-CoV-2), is a multifaceted disease characterized by a wide range of clinical presentations and degrees of severity (2). In the beginning, the target organ seemed to be only the respiratory system, inducing severe pneumonia and acute respiratory distress syndrome. However, an important lesson learned was that SARS-CoV-2 causes a high prothrombotic state, venous, and arterial thrombosis (1). The clinical presentation eventually resembles a thrombotic storm observed in vasculitis, disseminated intravascular coagulation, heparin-induced thrombocytopenia, 
and thrombophilia (3). Additionally, thrombosis mechanisms linking inflammation pathways, endothelial activation, coagulation system activity, immunothrombosis, cytokine storm, and renin-angiotensinaldosterone system dysregulation (4-8) seem to be involved.

Therefore, in severe COVID-19, venous thromboembolism (VTE) emerges as a critical and frequent complication $(9,10)$, with a high incidence $(15.3 \%)$ and mortality rate $(45.1 \%)$, in pulmonary embolism (PE) patients (11). Although there is a trend to better survival in patients treated with heparins (anticoagulation and anti-inflammatory effect) $(12,13)$, we do not have enough data on the best primary prevention doses, therapeutic approaches, and outcomes $(9,14,15)$. Also, there are no advanced treatment recommendations in massive and submassive PE $(16,17)$. Therefore, we performed a systematic review using the Preferred Reporting Items for Systematic Reviews and Metanalyses (PRISMA) statement to determine the therapeutic trends and outcomes in VTE COVID-19 patients. Also, we assessed the original Pulmonary Embolism Severity Index (PESI) in PE patients.

\section{Methods}

\section{Search strategy}

We searched for systematic reviews, cohorts, case series, case reports, editor letters, and VTE COVID-19 patients' abstracts through the PRISMA statement search (18). We register the protocol in the International Prospective Register protocol of Systematic Reviews (PROSPERO); registration number: CRD42020203688). The patients must have received anticoagulation or thrombolysis. The objective was to assess the therapeutic trends and clinical outcomes of VTE COVID-19 patients.

Additionally, we analyzed the clinical presentation, risk stratification, and diagnostic approach. We included deep vein thrombosis (DVT) and PE confirmed by an imaging method (venous doppler US, ventilation-perfusion lung scan, computed tomography pulmonary angiogram, pulmonary angiography). We assessed the original PESI since it works better than the simplified PESI (19). We established two groups, survivors and those who died. We performed a systematic review through PubMed, Scopus, Web of Science, Wiley, and OpenGrey and provided the complete search strategies in the e-Appendix. We used the snowballing method (20), a manual search to avoid lost reports, controlled vocabulary, and no language restriction. We do not contact authors to obtain additional information in cases with critical missing variables.

\section{Study selection and data collection}

We identified potentially eligible studies by examining titles and abstracts. We obtained full papers to assess eligibility criteria before the critical appraisal and extracted cases that met the eligibility criteria. All investigators analyzed data extraction of every case report to improve quality data extraction. The corresponding author is a cardiologist with expertise in the field (CJS). We conducted a group discussion daily to assess all the information extracted from the cases included in a database. Disagreements were solved posteriorly by consensus. We performed two meetings to ensure the data's quality through a 
random review of $20 \%$ of the papers. The primary outcomes were the therapeutic approaches, in-hospital death, intracranial hemorrhage (ICH), major bleeding, and minor bleedings.

Additionally, we analyzed the clinical presentation, the PE risk, COVID-19 severity, VTE primary prevention, and the thrombus's location in the pulmonary circulation. According to the International Society of Thrombosis and Haemostasis criteria, we defined major bleedings (21); we established the presence of right ventricular dysfunction according to the European Society of Cardiology guidelines of PE: right ventricular end-diastolic diameter/left ventricular end-diastolic diameter ratio $\geq 2: 1$, (b) regional or global right ventricular hypokinesis, (c) McConnell's sign, (d) right ventricular diameter $>35 \mathrm{~mm}$, (e) systolic pulmonary arterial pressure $\geq 50 \mathrm{~mm} \mathrm{Hg}$; B-type brain natriuretic peptide (BNP) measurement (>90 $\mathrm{pg} / \mathrm{mL}$ ) or N-terminal proBNP (NT-proBNP) $\left(>300 \mathrm{pg} / \mathrm{mL}\right.$ ) ${ }^{2}$; dynamic electrocardiographic changes (new complete or incomplete right bundle-branch block, anteroseptal ST elevation or depression, or anteroseptal T-wave inversion) (22); other definitions, including the PESI score, massive PE and intensive care unit (ICU) VTE risk factors, are available in the e-Appendix.

\section{Exploratory analysis}

Based on the high SARS-CoV-2 thrombogenicity and to understand its behavior in the venous system, we also analyzed acute cerebral vein thrombosis (CVT) associated or not with VTE.

\section{Statistical analysis}

We used summary statistics for continuous and categorical variables according to their types and distributions. We report the frequency and percentage $(n>20)$ for categorical variables, and for continuous variables, we report the median and standard deviation. We used the IBM SPSS $®$ software platform for advanced statistical analysis.

\section{Results}

We carried out the systematic review from August 9 to August 30, 2020. Figure 1 shows the flowchart, including the four phases of PRISMA, and we obtained, eliminated, and excluded duplicated reports. In the identification phase, we collected 1,535 papers from PubMed, Scopus, Web of Science, Wiley, and Opengrey. We carefully reviewed the full text for eligibility criteria and selected 107 reports for the quality assessment. Finally, we extracted the data for this review from 89 studies.

\section{Baseline demographics and primary outcomes}

Table 1 shows baseline characteristics, VTE classification, PE risk stratification, therapeutic trends, and survival and death patients' outcomes. We identified 143 COVID-19 patients with VTE; most were relatively young overweight males with isolated PE with or without proximal DVT. The proportion of lowrisk and submassive PE was higher in patients who survived than those who died, where massive PE was predominant (Table 1). In this group, the detection of proximal or distal DVT was scarce. Unfractionated 
and low-molecular-weight heparin drove parenteral anticoagulation in both groups. Also, direct-acting oral anticoagulant use was rare. The Food and Drug Administration-approved alteplase regimen drove the advanced treatment in both groups (Table 1). The mortality was high (21.6\%), and there was a low incidence of bleeding complications, including $\mathrm{ICH}$, in those who survived (Table 1). Table 2 shows the key findings related to medical history, patient and in-hospital risk factors, clinical presentation, PESI, and the setting of symptoms onset. Among the usual comorbidities in COVID-19, hypertension had a higher incidence in patients who died. The most prevalent VTE risk factors had a relationship with in-hospital and ICU stays in patients who died (Table 2). The earliest clinical PE findings were severe oxygen desaturation and sudden dyspnea, and leg pain in DVT survived patients (Table 2). A remarkable characteristic was the lowest oxygen saturation in those who died. The original PESI class II and III identified patients who lived (Table 2). Finally, patients with acute VTE events at home were more likely to live than in-hospital events. 
Table 1

Baseline demographics, VTE classification, risk stratification, therapeutic approaches and outcomes

\begin{tabular}{|c|c|c|c|}
\hline Variables & $\begin{array}{l}\text { All Patients } \\
\mathrm{N}=143(\%)\end{array}$ & $\begin{array}{l}\text { Survival } \\
N=112(\%)\end{array}$ & $\begin{array}{l}\text { Death } \\
\mathrm{N}=\mathbf{3 1}(\%)\end{array}$ \\
\hline Age (years), mean $\pm S D$ & $58.5 \pm 12.7$ & $58.1 \pm 13.6$ & $60.0 \pm 8.8$ \\
\hline Gender (male) & $91(63.6)$ & $70(62.5)$ & $21(67.7)$ \\
\hline $\mathrm{BMI}\left(\mathrm{kg} / \mathrm{m}^{2}\right)$, mean $\pm \mathrm{SD}$ & $30.9 \pm 5.6$ & $30.3 \pm 5.6$ & $31.6 \pm 5.6$ \\
\hline \multicolumn{4}{|l|}{ VTE classification } \\
\hline Isolated pulmonary embolism & $112(78.3)$ & $85(75.9)$ & $27(87.1)$ \\
\hline Isolated deep venous thrombosis & $12(8.4)$ & $10(8.9)$ & $2(6.5)$ \\
\hline Pulmonary embolism plus DVT & $18(12.6)$ & $16(14.3)$ & $2(6.5)$ \\
\hline Pulmonary embolism plus CVT & $1(0.7)$ & $1(0.9)$ & $0(0)$ \\
\hline \multicolumn{4}{|l|}{ PE risk stratification (ACC/AHA) } \\
\hline Low risk & $24(18.3)$ & $23(20.5)$ & $1(3.2)$ \\
\hline Submassive & $31(23.7)$ & $29(25.9)$ & $2(6.5)$ \\
\hline Massive & $39(29.8)$ & $21(18.8)$ & $18(58)$ \\
\hline Unable to classify & $37(28.2)$ & $29(25.9)$ & $8(25.8)$ \\
\hline \multicolumn{4}{|l|}{ DVT classification } \\
\hline Proximal DVT & $14(9.8)$ & $11(9.8)$ & $3(9.7)$ \\
\hline Distal DVT & $5(3.5)$ & $5(4.5)$ & $0(0)$ \\
\hline Proximal plus distal DVT & $5(3.5)$ & $5(4.5)$ & $0(0)$ \\
\hline Upper limb DVT & $6(4.2)$ & $4(3.6)$ & $2(6.5)$ \\
\hline \multicolumn{4}{|l|}{ Treatment } \\
\hline Unfractionated heparin & $28(19.6)$ & $22(19.6)$ & $6(19.4)$ \\
\hline Low-molecular-weight-heparin & $57(39.9)$ & $49(43.8)$ & $8(25.8)$ \\
\hline Warfarin & $0(0)$ & $0(0)$ & $0(0)$ \\
\hline Fondaparinoux & $3(2.1)$ & $3(2.7)$ & $0(0)$ \\
\hline Direct oral anticoagulants & $8(5.6)$ & $8(7.1)$ & $0(0)$ \\
\hline
\end{tabular}

VTE: venous thromboembolism; DVT: deep venous thrombosis; CVT: cerebral venous thrombosis; DOACs: direct-acting oral anticoagulants. 


\begin{tabular}{|llll|}
\hline Variables & All Patients & Survival & Death \\
& $\mathbf{N = 1 4 3 ( \% )}$ & $\mathbf{N = 1 1 2 ( \% )}$ & $\mathbf{N}=\mathbf{3 1}(\%)$ \\
\hline Apixaban & $4(2.8)$ & $4(3.6)$ & $0(0)$ \\
\hline Rivaroxaban & $2(1.4)$ & $2(1.8)$ & $0(0)$ \\
\hline Unspecified DOACs & $2(1.4)$ & $2(1.8)$ & $0(0)$ \\
\hline Alteplase 100 mg & $33(23.1)$ & $20(17.9)$ & $13(41.9)$ \\
\hline Alteplase 50 mg & $6(4.2)$ & $4(3.6)$ & $2(6.5)$ \\
\hline Tenecteplase & $1(0.7)$ & $0(0)$ & $1(3.2)$ \\
\hline CDT & $1(0.7)$ & $1(0.9)$ & $0(0)$ \\
\hline USCDT & $3(2.1)$ & $3(2.7)$ & $0(0)$ \\
\hline Mechanical thrombectomy & $3(2.1)$ & $3(2.7)$ & $0(0)$ \\
\hline Surgical thrombectomy & $4(2.8)$ & $3(2.7)$ & $1(3.2)$ \\
\hline Outcomes & & & $31(21.6)$ \\
\hline Death & $143(100)$ & $112(78.39)$ & $1(3.2)$ \\
\hline Intracranial hemorrhage & $2(1.4)$ & $1(0.9)$ & $1(3.2)$ \\
\hline Major bleeding & $2(1.4)$ & $1(0.9)$ & $1(3.2)$ \\
\hline Minor bleeding & $2(1.4)$ & $1(0.9)$ & \\
\hline VTE: venous thromboembolism; DVT: deep venous thrombosis; CVT: cerebral venous thrombosis; & & & \\
\hline DOACs: direct-acting oral anticoagulants. & & & \\
\hline
\end{tabular}


Table 2

VTE risk factors, clinical presentation, PESI and onset

\begin{tabular}{|c|c|c|c|}
\hline \multirow[t]{2}{*}{ Variables } & All patients & Survival & Death \\
\hline & $N=143(\%)$ & $N=112(\%)$ & $N=31(\%)$ \\
\hline \multicolumn{4}{|l|}{ Medical history and risk factors } \\
\hline Hypertension & $50(35)$ & $34(30.4)$ & $16(51.6)$ \\
\hline Diabetes & $33(23.1)$ & $25(22.3)$ & $8(25.8)$ \\
\hline Lung disease & $16(11.2)$ & $15(13.4)$ & $1(3.2)$ \\
\hline Medical history of cancer & $7(4.9)$ & $5(4.5)$ & $2(6.5)$ \\
\hline Active cancer & $5(3.5)$ & $3(2.7)$ & $2(6.5)$ \\
\hline Previous venous thromboembolism & $2(1.4)$ & $2(1.8)$ & $0(0)$ \\
\hline \multicolumn{4}{|l|}{ In-hospital and ICU risk factors } \\
\hline Immobilization & $88(61.5)$ & $63(56.3)$ & $25(80.6)$ \\
\hline Sedation & $51(35.7)$ & $27(24.1)$ & $24(77.4)$ \\
\hline Central venous lines & $52(36.4)$ & $28(25)$ & $24(77.4)$ \\
\hline Vasopressors & $15(10.5)$ & $4(3.6)$ & $11(35.5)$ \\
\hline \multicolumn{4}{|l|}{ VTE Clinical presentation } \\
\hline $\mathrm{O}^{2}$ saturation $(\%)$, mean $\pm \mathrm{SD}$ & $87.9 \pm 7.6$ & $88.3 \pm 7.4$ & $85 \pm 9.4$ \\
\hline Sudden dyspnea & $31(21.7)$ & $29(25.9)$ & $2(6.5)$ \\
\hline Progressive dyspnea & $26(18.2)$ & $23(20.5)$ & $3(9.7)$ \\
\hline Pleuritic chest pain & $20(14)$ & $19(17)$ & $1(3.2)$ \\
\hline Ischemic chest pain & $2(1.4)$ & $2(1.8)$ & $0(0)$ \\
\hline Leg pain & $13(9.1)$ & $11(9.8)$ & $2(6.5)$ \\
\hline \multicolumn{4}{|l|}{ Original PESI } \\
\hline I (Very low risk) & $13(9.1)$ & $13(11.6)$ & $0(0)$ \\
\hline II (Low risk) & $27(18.9)$ & $25(22.3)$ & $2(6.5)$ \\
\hline III (Intermediate risk) & 45 (31.5) & $37(33)$ & $8(25.8)$ \\
\hline IV (High risk) & $11(7.7)$ & $11(9.8)$ & $0(0)$ \\
\hline V (Very high risk) & $35(24.5)$ & $19(17)$ & $16(51.6)$ \\
\hline
\end{tabular}




\begin{tabular}{|llll|}
\hline Variables & All patients & Survival & Death \\
& $\mathbf{N}=\mathbf{1 4 3}(\%)$ & $\mathbf{N = 1 1 2 ( \% )}$ & $\mathbf{N = 3 1 ( \% )}$ \\
\hline Home & $53(37.1)$ & $48(42.9)$ & $5(16.1)$ \\
\hline In-hospital & $90(62.9)$ & $64(57.1)$ & $26(83.9)$ \\
\hline
\end{tabular}

Table 3 shows the use of biomarkers and imaging studies in both groups. Patients who died had a higher D dimer expression and right ventricular dysfunction (Table 3). Biomarker use was even low guidelines recommendations (22) (Table 3). The computed tomography pulmonary angiography (CTPA) demonstrated a wide distribution of thrombus locations in surviving patients (Table 3). Table 4 shows the clinical presentation, laboratory, imaging findings, and primary prevention in COVID-19. The variables mainly related to mortality were acute respiratory distress syndrome, mechanical ventilation, ICU stay, and higher $\mathrm{C}$ reactive protein measurements in PE patients. We also identified reduced thromboprophylaxis use in both groups.

Table 3

Biomarkers and imaging studies in venous thromboembolism COVID-19 patients

\begin{tabular}{|llll|}
\hline Variables & All patients & Survival & Death \\
& $\mathbf{N}=\mathbf{1 4 3}(\%)$ & $\mathbf{N = 1 1 2}(\%)$ & $\mathbf{N = 3 1}(\%)$ \\
\hline Biomarkers & & & \\
\hline D-dimer $(\mathrm{mcg} / \mathrm{mL})$, median (IQR) & $\begin{array}{l}7794(3320- \\
17460)\end{array}$ & $\begin{array}{l}7700(3200- \\
16125)\end{array}$ & $\begin{array}{l}8897(4352- \\
33175)\end{array}$ \\
\hline Hs-cTn (ng/mL), median (IQR) & $57(14.5-191)$ & - & - \\
\hline Ferritin $(\mathrm{ng} / \mathrm{mL})$, median (IQR) & $765(402-1456)$ & - & - \\
\hline Imaging studies & & & $21(67.8)$ \\
\hline $\begin{array}{l}\text { Right ventricular dysfunction } \\
\text { (TTE) }\end{array}$ & $56(39.2)$ & $35(31.3)$ & $1(3.2)$ \\
\hline CTPA & & & $4(12.9)$ \\
\hline Saddle PE & $10(7)$ & $9(8)$ & $3(9.7)$ \\
\hline Main branches & $38(26.6)$ & $34(30.4)$ & $4(12.9)$ \\
\hline Lobar branches & $22(15.4)$ & $19(17)$ & $0(0)$ \\
\hline Segmental branches & $27(18.9)$ & $23(20.5)$ & $5(16.1)$ \\
\hline Subsegmental branches & $7(4.9)$ & $7(6.3)$ & $25(22.3)$ \\
\hline Doppler US and DVT & $30(20.9)$ & & \\
\hline
\end{tabular}


Page 11/24 
Table 4

COVID-19 characteristics

\begin{tabular}{|c|c|c|c|}
\hline \multirow[t]{2}{*}{ Variables } & All patients & Survival & Death \\
\hline & $N=143(\%)$ & $N=112(\%)$ & $\mathrm{N}=31(\%)$ \\
\hline \multicolumn{4}{|l|}{ COVID-19 severity } \\
\hline Asymptomatic & $14(9.8)$ & $12(10.7)$ & $2(6.5)$ \\
\hline Mild symptoms & $9(6.3)$ & $8(7.1)$ & $1(3.2)$ \\
\hline Fever & $27(18.9)$ & $23(20.5)$ & $4(12.9)$ \\
\hline Pneumonia & $62(43.4)$ & $55(49.1)$ & $7(22.6)$ \\
\hline ARDS & $58(40.6)$ & $37(33)$ & $21(67.7)$ \\
\hline Mechanical ventilation & $56(39.2)$ & $32(28.6)$ & $24(77.4)$ \\
\hline ICU & $69(48.3)$ & $40(35.7)$ & $29(93.5)$ \\
\hline \multicolumn{4}{|l|}{ Laboratories } \\
\hline Leukocytes $\left(10^{(9)} \mathrm{u} / \mathrm{L}\right)$, median (IQR) & $11.9(9.7-15.4)$ & $11.4(9.4-13.6)$ & $13.8(10.8-20.3)$ \\
\hline Lymphocytes $\left(10^{(3)} \mathrm{u} / \mathrm{L}\right)$, mean \pm SD & $928.3 \pm 448.5$ & $994.1 \pm 461.5$ & $731.1 \pm 360.1$ \\
\hline Platelets $\left(10^{(3)} \mathrm{u} / \mathrm{L}\right)$, mean $\pm \mathrm{SD}$ & $246.8 \pm 129.8$ & $254.4 \pm 122.9$ & $233.7 \pm 143.7$ \\
\hline LDH (U/L), median (IQR) & $575(391.8-739.3)$ & - & - \\
\hline CRP (mg/L), median (IQR) & $113.1(50.6-222.5)$ & $92.9(50-160)$ & $244.9(154-345.4)$ \\
\hline RT-PCR SARS-CoV-2 (+) & $142(99.3)$ & $111(99.1)$ & $31(100)$ \\
\hline \multicolumn{4}{|l|}{ Imagen studies } \\
\hline Bilateral infiltrates (chest X-ray) & $49(34.3)$ & $37(33)$ & $12(38.7)$ \\
\hline CT with CO-RADS 5 & $49(34.3)$ & $43(38.4)$ & $6(19.4)$ \\
\hline \multicolumn{4}{|l|}{ Thromboprophylaxis } \\
\hline Unfractionated heparin & $17(11.9)$ & $11(9.8)$ & $6(19.4)$ \\
\hline Low-molecular weight heparin & $31(21.7)$ & $20(17.9)$ & $11(35.5)$ \\
\hline Unspecified & $3(2.1)$ & $2(1.8)$ & $1(3.2)$ \\
\hline Not received & $89(62.2)$ & $77(68.8)$ & $12(38.7)$ \\
\hline \multicolumn{4}{|l|}{ Previous anticoagulation treatment } \\
\hline Direct-acting oral anticoagulants & $1(0.7)$ & $1(0.9)$ & $0(0)$ \\
\hline
\end{tabular}




\begin{tabular}{|llll|}
\hline Variables & All patients & Survival & Death \\
& $\mathbf{N}=\mathbf{1 4 3}(\%)$ & $\mathbf{N}=\mathbf{1 1 2}(\%)$ & $\mathbf{N = 3 1}(\%)$ \\
\hline VKA & $2(1.4)$ & $1(0.9)$ & $1(3.2)$ \\
\hline
\end{tabular}

\section{Exploratory Analysis}

We identified 15 young patients with a similar gender proportion practically without a history of contraceptives (Table 5). CVT clinical presentation included neurologic alterations at home, abnormal D dimer measurements, and only one case associated with a submassive PE. Most patients were asymptomatic or had COVID-19 pneumonia. Despite in-hospital primary prevention, five patients had CVT. We identified a remarkably high prevalence of $\mathrm{ICH}(10 / 15$ patients) and increased mortality (3/15 patients) (Table 5). 
Table 5

Exploratory analysis: cerebral vein thrombosis

\begin{tabular}{|c|c|}
\hline Variables & $N=15$ \\
\hline Age & $56 \pm 14.3$ \\
\hline Gender (male) & 7 \\
\hline \multicolumn{2}{|l|}{ Risk factors } \\
\hline Comorbidities ( $\geq 1$ ) & 2 \\
\hline Oral contraceptives & 2 \\
\hline D-dimer $(\mathrm{mcg} / \mathrm{mL})$, mean $\pm \mathrm{SD}$ & $3698.4 \pm 2017.3$ \\
\hline Submassive pulmonary embolism & 1 \\
\hline \multicolumn{2}{|l|}{ CVT presentation } \\
\hline Altered mental status & 6 \\
\hline Headache & 8 \\
\hline Aphasia & 6 \\
\hline Hemiparesis & 7 \\
\hline Seizures & 4 \\
\hline At home & 9 \\
\hline \multicolumn{2}{|l|}{ COVID-19 clinical presentation } \\
\hline Fever & 3 \\
\hline Progressive dyspnea & 3 \\
\hline Asymptomatic & 3 \\
\hline Mild symptoms & 1 \\
\hline Pneumonia & 6 \\
\hline CT with CO-RADS 5 & 6 \\
\hline Thromboprophylaxis & 5 \\
\hline \multicolumn{2}{|l|}{ Treatment and outcomes } \\
\hline Unfractionated heparin & 3 \\
\hline Low-molecular-weight-heparin & 12 \\
\hline Intracranial hemorrhage & 7 \\
\hline Death & 3 \\
\hline
\end{tabular}

Page $14 / 24$ 


\section{Discussion}

This systematic review highlights the therapeutic trends and outcomes of VTE survivors compared with those who died. The main observations were: First, unfractionated and low-molecular-weight heparin was the cornerstone in the VTE treatment. Also, the Food and Drug Administration-approved systemic alteplase regimen drives advanced therapy in PE patients. Second, we identified high mortality in the ICU associated with severe COVID-19 with a low incidence of bleeding complications in massive PE. Third, the original PESI score II-III recognized patients who survived, suggesting its usefulness in the risk stratification in COVID-19 patients. Fourth, elevated $C$ reactive protein and D dimer measurements and right ventricular dysfunction identified poor in-hospital outcomes. Finally, the exploratory analysis showed the same high ICH incidence in CVT mild COVID-19 patients than non-COVID-19 patients.

Recent systematic reviews and meta-analyses focused on the incidence, primary and secondary VTE prevention, bleeding complications (23-26), and the association of D-dimer with mortality $(27,28)$. Therefore, therapeutic approaches, outcomes, clinical presentation, risk stratification, and patient characteristics are not well defined.

Patients with severe COVID-19 disease are at high risk for thromboinflammation since they have SARSCoV-2 infection, risk factors, cardiovascular, renal, or chronic pulmonary inflammatory comorbidities (2). An increased frequency of arterial and venous thrombosis at the beginning of the pandemic was remarkable (29). VTE is now recognized as among the predominant cardiovascular hazards (29), with the highest incidence in the intensive care unit setting (25\%), increasing to $69 \%$ after surveillance venous ultrasonography (29). Also, thromboprophylaxis, the foundation to prevent in-hospital VTE, fails in a subset of COVID-19 patients (29). Additionally, quantifying the risk of thrombosis and cardiovascular complications is complicated in this heterogeneous population by reports of limited sample size, restriction of assessments to the ICU setting, outcome definitions, and differing thromboprophylaxis strategies (29).

Our findings suggest that intravenous or subcutaneous anticoagulation remains the cornerstone of therapy in deep venous thrombosis and PE COVID-19 patients. Strategies for reperfusion therapy included the thrombolysis regimen recommended for international guidelines (22) or "safe dose" in PE patients (30-32) (Table 1). The rationale for systemic fibrinolysis in PE is to avert or improve impending clinical instability secondary to right ventricular dysfunction to improve the outcome. Several pulmonary hypertension mechanisms ( $\mathrm{PE}$, hypoxic vasoconstriction, pulmonary microthrombi, ACE2 dysregulation, and cytokine storm) inducing right ventricular dysfunction demand a CTPA before clinical decisionmaking in this population (33). Despite systemic thrombolysis, bleeding complication incidence was lower ( $0.9 \%$ vs. $3.2 \%$; Table 1$)$ than recent evidence $(21.4 \%)$ using intermediate- or full-heparin dose without advanced treatment and bleeding definitions according to the individual studies (26). This difference in the incidence of bleeding complications is unclear because relevant clinical or significant bleedings are usually reported. We showed high mortality (21.6\%) in massive PE in SARS-CoV-2 infected individuals with severe COVID-19 (Table 1). However, it is lower than observed in massive PE non-COVID- 
19 patients (33\%) (34); the mortality rates observed are also related to severe COVID-19 and higher than previous other viral pandemics experienced in the past (35).

The original PESI score is a helpful tool for immediate and bedside risk stratification (22); whether this score helps COVID-19 patients is unanswered. The original PESI risk score had greater precision in identifying low and intermediate PE risks and identified a high proportion of high-risk patients with very high risk (19) (Table 2). Current COVID-19 restrictions delay or avoid all recommended diagnostic approaches in high clinical suspicion PE patients (22); thus, the original PESI score could be helpful in high clinical suspicion COVID-19 patients. Clinicians should also consider that the simplified PESI score may fail (36), and a multimodal approach use improves the accuracy of risk stratification. (PESI score definition is available in the e-Appendix).

The main characteristics of patients who died included hypertension, a high inflammatory, and prothrombotic state, severe COVID-19 associated with massive PE, ICU admission, and low use of VTE primary prevention (Tables 2, 3, and 4). Another remarkable finding shows VTE events despite thromboprophylaxis. Current evidence suggests administering heparin at standard doses in non-critically ill patients without risk factor for thrombosis or at a high dose for critically ill patients (intermediate or therapeutic dose) (37). Additionally, high dose thromboprophylaxis might be adjusted according to inflammation's progression without increasing bleeding risk in critically ill COVID-19 patients (38). Randomized controlled trials comparing different thromboprophylaxis doses are needed to establish the best therapeutic approach (38). The most consistent biomarker abnormalities related to mortality were higher C-reactive protein and D-dimer measurement levels, both associated with ICU admission and death (15). Patients with severe COVID-19 are at increased risk of thromboinflammation as they have proinflammatory risk factors, cardiopulmonary comorbidities related to inflammation, and cytokine storm (33). Additionally, there are several plausible reasons for elevated D-dimer in patients with SARS-CoV-2: severe infection, VTE, pulmonary and coronary microthrombus, acute kidney, cardiac injury, and proinflammatory cytokines (28).

Overlapping severe COVID-19 pneumonia and PE is a challenge, and any pneumonia increases the risk of VTE (33). A higher D-dimer measurement and severe oxygen desaturation are possible clinical markers to establish high clinical suspicion and PE severity. Recently, in a case series, the clinical presentation was similar: persistent or worsening respiratory symptoms increased oxygen requirements and DD levels that were several-fold higher (39). We suggest that physicians in charge should consider these clinical variables and never ignore abnormal or significantly elevated D-dimer because it is an expression of the coagulation system and secondary fibrinolysis activity, suggesting a high risk of acute thrombosis or, at least, VTE (33). Sudden hypotension could be another clinical element for PE suspicion in the setting of pneumonia COVID-19 (33).

We identified differences in the baseline characteristics reported previously in CVT patients (40-42). Only two patients had a history of oral contraceptives and no history of hereditary prothrombotic factors. These findings suggest an essential role of SARS-CoV-2 in pathogenicity as a trigger of thrombosis. 
Although early $\mathrm{ICH}$ (present at the time of diagnosis) is a frequent complication $(40 \%)(41,42)$, current evidence demonstrates a low incidence of new ICH after initiating treatment with anticoagulation (4043). This analysis identified a high ICH incidence (four early and six after treatment), secondary to a high pro-inflammatory state induced by SARS-CoV-2. Although anticoagulation is the standard of care in CVT patients (avoid thrombus growth, prevent VTE), the high prevalence of ICH suggests that physicians in charge have to be warning for early detection of this feared complication (42).

The significant limitations of the study included a potential loss of case reports from search engines. There is a trend not to report patients with poor in-hospital outcomes or serious adverse events. It was not possible to obtain information on the timing of the D-dimer measurements and other biomarkers. We got the most information from case reports, and we did not contact any author. As for any systematic review, our results should be considered hypothesis-generating; prospective studies are mandatory to confirm our findings.

\section{Conclusion}

In this systematic review analyzing 143 survivors and non-survivors VTE COVI-19 patients, we determined a high mortality incidence of PE (21.6\%) related to hypertension, a high inflammatory, prothrombotic state, severe COVID-19, massive PE, ICU admission, and low VTE prophylaxis, and bleeding complications. Overlapping severe COVID-19 pneumonia and PE is a challenge. A higher D-dimer measurement and severe oxygen desaturation are possible clinical markers to establish a high-clinical suspicion and severity PE. The original PESI could be useful in risk stratification. Prospective clinical trials are mandatory to elucidate the optimal primary or secondary prevention and advanced treatment in this population of patients.

\section{Abbreviations}

coronavirus disease 2019 (COVID-19); severe acute respiratory syndrome coronavirus 2 (SARS-CoV-2); venous thromboembolism (VTE); pulmonary embolism (PE); original Pulmonary Embolism Severity Index (PESI); the International Prospective Register protocol of Systematic Reviews (PROSPERO); the Preferred Reporting Items for Systematic Reviews and Metanalyses (PRISMA); deep vein thrombosis (DVT); simplified Pulmonary Embolism Severity Index (PESI); B-type brain natriuretic peptide (BNP); N-terminal proBNP (NT-proBNP); cerebral vein thrombosis (CVT); intensive care unit (ICU); intracranial hemorrhage (ICH); computed tomography pulmonary angiography (CTPA)

\section{Declarations}

\section{Ethics approval and consent to participate:}

Not applicable

\section{Consent for publication:}


Not applicable

\section{Availability of data and materials:}

Not applicable

\section{Competing interests:}

The authors declare that they have no competing interests

\section{Funding:}

None

\section{Authors' contributions:}

MCP: Substantial contributions to the conception, design of the work; research idea development; database; the acquisition, analysis, interpretation of data; have drafted the work and substantively revised it.

CJS: Leaded the research team, research idea development, revising and approving the project design, and moderating group discussions. Also, elaborated the project's protocol and final tables and manuscripts.

ACV: The data acquisition, have drafted the work and substantively revised it. Contributed to the revision of the database, and the elaboration and revision of the tables and final manuscript.

JGPV: The data acquisition, database; have drafted the work and substantively revised it.

EVG: Acquisition and analysis of the database, and interpretation of initial data. Have drafted the work and substantively revised it

RERC: Managed the systematic search alongside MCP, created the database, collected, and interpreted data.

JASC: Acquisition and analysis of the database and interpretation of initial data. Have drafted the work and substantively revised it.

AMMR: Acquisition and analysis of the database and interpretation of initial data. Have drafted the work and substantively revised it.

AAMI: Acquisition and analysis of the database and interpretation of initial data. Have drafted the work and substantively revised it.

MAF: The design of the work, data acquisition and revision of the manuscript 
YZFS: Acquisition and analysis of the database and interpretation of initial data. Have drafted the work and substantively revised it.

JAGL: Acquisition and analysis of the database and interpretation of initial data. Have drafted the work and substantively revised it.

HLG: data acquisition, analysis, and interpretation; Have drafted the work and substantively revised it.

HBC: Acquisition and analysis of the database and interpretation of initial data. Have drafted the work and substantively revised it.

DMM: contributions to the design, data interpretation, interpretation of initial data. Have drafted the work and substantively revised it.

JP: Acquisition and analysis of the database, and interpretation of initial data. Have drafted the work and substantively revised it.

\section{Acknowledgment:}

Not applicable

\section{References}

1. McFadyen JD, Stevens H, Peter K. The Emerging Threat of (Micro)Thrombosis in COVID-19 and Its Therapeutic Implications. Circ Res. el 31 de julio de 2020;127(4):571-87.

2. Chen T, Wu D, Chen H, Yan W, Yang D, Chen G, et al. Clinical characteristics of 113 deceased patients with coronavirus disease 2019: retrospective study. BMJ. el 26 de marzo de 2020;m1091.

3. Becker RC. COVID-19 update: Covid-19-associated coagulopathy. J Thromb Thrombolysis. julio de 2020;50(1):54-67.

4. Vazquez-Garza E, Jerjes-Sanchez C, Navarrete A, Joya-Harrison J, Rodriguez D. Venous thromboembolism: thrombosis, inflammation, and immunothrombosis for clinicians. J Thromb Thrombolysis. octubre de 2017;44(3):377-85.

5. Archer SL, Sharp WW, Weir EK. Differentiating COVID-19 Pneumonia from Acute Respiratory Distress Syndrome (ARDS) and High Altitude Pulmonary Edema (HAPE): Therapeutic Implications. Circulation. el 5 de mayo de 2020;CIRCULATIONAHA.120.047915.

6. Fox SE, Akmatbekov A, Harbert JL, Li G, Brown JQ, Vander Heide RS. Pulmonary and Cardiac Pathology in Covid-19: The First Autopsy Series from New Orleans [Internet]. Pathology; 2020 abr [citado el 14 de abril de 2020]. Disponible en: http://medrxiv.org/lookup/doi/10.1101/2020.04.06.20050575

7. Vaduganathan M, Vardeny O, Michel T, McMurray JJV, Pfeffer MA, Solomon SD. Renin-AngiotensinAldosterone System Inhibitors in Patients with Covid-19. N Engl J Med. el 23 de abril de 
2020;382(17):1653-9.

8. Poor HD, Ventetuolo CE, Tolbert T, Chun G, Serrao G, Zeidman A, et al. COVID-19 Critical Illness Pathophysiology Driven by Diffuse Pulmonary Thrombi and Pulmonary Endothelial Dysfunction Responsive to Thrombolysis [Internet]. Respiratory Medicine; 2020 abr [citado el 2 de mayo de 2020]. Disponible en: http://medrxiv.org/lookup/doi/10.1101/2020.04.17.20057125

9. Atri D, Siddiqi HK, Lang J, Nauffal V, Morrow DA, Bohula EA. COVID-19 for the Cardiologist: A Current Review of the Virology, Clinical Epidemiology, Cardiac and Other Clinical Manifestations and Potential Therapeutic Strategies. JACC Basic TransI Sci. abril de 2020;S2452302X20301571.

10. Poissy J, Goutay J, Caplan M, Parmentier E, Duburcq T, Lassalle F, et al. Pulmonary Embolism in COVID-19 Patients: Awareness of an Increased Prevalence. Circulation. el 24 de abril de 2020;CIRCULATIONAHA.120.047430.

11. Liao S-C, Shao S-C, Chen Y-T, Chen Y-C, Hung M-J. Incidence and mortality of pulmonary embolism in COVID-19: a systematic review and meta-analysis. Crit Care. diciembre de 2020;24(1):464.

12. Tang N, Bai H, Chen X, Gong J, Li D, Sun Z. Anticoagulant treatment is associated with decreased mortality in severe coronavirus disease 2019 patients with coagulopathy. $J$ Thromb Haemost [Internet]. el 27 de marzo de 2020 [citado el 14 de abril de 2020]; Disponible en: http://doi.wiley.com/10.1111/jth.14817

13. Thachil J. The versatile heparin in COVID-19. J Thromb Haemost [Internet]. el 2 de abril de 2020 [citado el 14 de abril de 2020]; Disponible en: http://doi.wiley.com/10.1111/jth.14821

14. Liu PP, Blet A, Smyth D, Li H. The Science Underlying COVID-19: Implications for the Cardiovascular System. Circulation. el 15 de abril de 2020;CIRCULATIONAHA.120.047549.

15. Bikdeli B, Madhavan MV, Jimenez D, Chuich T, Dreyfus I, Driggin E, et al. COVID-19 and Thrombotic or Thromboembolic Disease: Implications for Prevention, Antithrombotic Therapy, and Follow-up. J Am Coll Cardiol. abril de 2020;S0735109720350087.

16. Wang J, Hajizadeh N, Moore EE, McIntyre RC, Moore PK, Veress LA, et al. Tissue Plasminogen Activator (tPA) Treatment for COVID-19 Associated Acute Respiratory Distress Syndrome (ARDS): A Case Series. J Thromb Haemost [Internet]. el 8 de abril de 2020 [citado el 14 de abril de 2020]; Disponible en: http://doi.wiley.com/10.1111/jth.14828

17. Oudkerk M, Büller HR, Kuijpers D, van Es N, Oudkerk SF, McLoud TC, et al. Diagnosis, Prevention, and Treatment of Thromboembolic Complications in COVID-19: Report of the National Institute for Public Health of the Netherlands. Radiology. el 23 de abril de 2020;201629.

18. Moher D, Liberati A, Tetzlaff J, Altman DG, The PRISMA Group. Preferred Reporting Items for Systematic Reviews and Meta-Analyses: The PRISMA Statement. PLoS Med. el 21 de julio de 2009;6(7):e1000097.

19. Vinson DR, Ballard DW, Mark DG, Huang J, Reed ME, Rauchwerger AS, et al. Risk stratifying emergency department patients with acute pulmonary embolism: Does the simplified Pulmonary Embolism Severity Index perform as well as the original? Thromb Res. diciembre de 2016;148:1-8. 
20. Greenhalgh T, Peacock R. Effectiveness and efficiency of search methods in systematic reviews of complex evidence: audit of primary sources. BMJ. el 5 de noviembre de 2005;331(7524):1064-5.

21. Schulman S, Kearon C, the SUBCOMMITTEE ON CONTROL OF ANTICOAGULATION OF THE SCIENTIFIC AND STANDARDIZATION COMMITTEE OF THE INTERNATIONAL SOCIETY ON THROMBOSIS AND HAEMOSTASIS. Definition of major bleeding in clinical investigations of antihemostatic medicinal products in non-surgical patients: Definitions of major bleeding in clinical studies. J Thromb Haemost. el 4 de abril de 2005;3(4):692-4.

22. Konstantinides SV, Meyer G, Becattini C, Bueno H, Geersing G-J, Harjola V-P, et al. 2019 ESC Guidelines for the diagnosis and management of acute pulmonary embolism developed in collaboration with the European Respiratory Society (ERS). Eur Heart J. el 31 de agosto de 2019;ehz405.

23. Lu Y, Pan L, Zhang W-W, Cheng F, Hu S-S, Zhang X, et al. A meta-analysis of the incidence of venous thromboembolic events and impact of anticoagulation on mortality in patients with COVID-19. Int $J$ Infect Dis. noviembre de 2020;100:34-41.

24. Porfidia A, Valeriani E, Pola R, Porreca E, Rutjes AWS, Di Nisio M. Venous thromboembolism in patients with COVID-19: Systematic review and meta-analysis. Thromb Res. diciembre de 2020;196:67-74.

25. Zhang C, Shen L, Le K-J, Pan M-M, Kong L-C, Gu Z-C, et al. Incidence of Venous Thromboembolism in Hospitalized Coronavirus Disease 2019 Patients: A Systematic Review and Meta-Analysis. Front Cardiovasc Med. el 6 de agosto de 2020;7:151.

26. Jiménez D, García-Sanchez A, Rali P, Muriel A, Bikdeli B, Ruiz-Artacho P, et al. Incidence of venous thromboembolism and bleeding among hospitalized patients with COVID-19: a systematic review and meta-analysis. Chest. noviembre de 2020;S0012369220351461.

27. Chi G, Lee JJ, Jamil A, Gunnam V, Najafi H, Memar Montazerin S, et al. Venous Thromboembolism among Hospitalized Patients with COVID-19 Undergoing Thromboprophylaxis: A Systematic Review and Meta-Analysis. J Clin Med. el 3 de agosto de 2020;9(8):2489.

28. Bansal A, Singh AD, Jain V, Aggarwal M, Gupta S, Padappayil RP, et al. The association of D-dimers with mortality, intensive care unit admission or acute respiratory distress syndrome in patients hospitalized with coronavirus disease 2019 (COVID-19): a systematic review and meta-analysis. Heart Lung. septiembre de 2020;S0147956320303800.

29. Piazza G, Campia U, Hurwitz S, Snyder JE, Rizzo SM, Pfeferman MB, et al. Registry of Arterial and Venous Thromboembolic Complications in Patients With COVID-19. J Am Coll Cardiol. noviembre de 2020;76(18):2060-72.

30. Sharifi M, Larijani F, Wycliffe R, Loggins B, Schroeder B, Monteros DDL, et al. LOW DOSE SYSTEMIC THROMBOLYSIS AND NEW ORAL ANTICOAGULANTS IN THE TREATMENT OF LARGE THROMBI IN THE RIGHT HEART. J Am Coll Cardiol. marzo de 2017;69(11):2079.

31. Sharifı M, Vajo Z, Freeman W, Bay C, Sharifı M, Schwartz F. Transforming and Simplifying the Treatment of Pulmonary Embolism: "Safe Dose" Thrombolysis Plus New Oral Anticoagulants. Lung. 
junio de 2015;193(3):369-74.

32. Sharifi M, Bay C, Schwartz F, Skrocki L. Safe-Dose Thrombolysis Plus Rivaroxaban for Moderate and Severe Pulmonary Embolism: Drip, Drug, and Discharge: Thrombolysis plus rivaroxaban in PE. Clin Cardiol. febrero de 2014;37(2):78-82.

33. Betancourt-del Campo H, Jerjes-Sanchez C, Castillo-Perez M, López-de la Garza H, Paredes-Vázquez JG, Flores-Sayavedra YZ, et al. Systemic thrombolysis and anticoagulation improved biomarker measurements in massive-like pulmonary embolism and severe COVID-19 pneumonia: a case report. Brown RA, Bouzas-Mosquera A, Cankovic MZ, Rampat R, Sayers M, Thomson R, editores. Eur Heart J - Case Rep. el 13 de diciembre de 2020;ytaa448.

34. Piazza G. Advanced Management of Intermediate- and High-Risk Pulmonary Embolism. J Am Coll Cardiol. noviembre de 2020;76(18):2117-27.

35. Malas MB, Naazie IN, Elsayed N, Mathlouthi A, Marmor R, Clary B. Thromboembolism risk of COVID19 is high and associated with a higher risk of mortality: A systematic review and meta-analysis. EClinicalMedicine. diciembre de 2020;29-30:100639.

36. Trevino AR, Perez L, Jerjes-Sanchez C, Rodriguez D, Panneflek J, Ortiz-Ledesma C, et al. Factor Xa inhibition and SPESI failure in intermediate-high-risk pulmonary embolism. Am J Emerg Med. octubre de 2018;36(10):1925.e3-1925.e4.

37. Susen S, Tacquard CA, Godon A, Mansour A, Garrigue D, Nguyen P, et al. Prevention of thrombotic risk in hospitalized patients with COVID-19 and hemostasis monitoring. Crit Care. diciembre de 2020;24(1):364.

38. Tacquard C, Mansour A, Godon A, Godet J, Poissy J, Garrigue D, et al. Impact of high dose prophylactic anticoagulation in critically ill patients with COVID-19 pneumonia. Chest. enero de 2021;S0012369221000477.

39. Faggiano P, Bonelli A, Paris S, Milesi G, Bisegna S, Bernardi N, et al. Acute pulmonary embolism in COVID-19 disease: Preliminary report on seven patients. Int J Cardiol. agosto de 2020;313:129-31.

40. de Bruijn SFTM, Stam J. Randomized, Placebo-Controlled Trial of Anticoagulant Treatment With Low-Molecular-Weight Heparin for Cerebral Sinus Thrombosis. Stroke. marzo de 1999;30(3):484-8.

41. Girot M, Ferro JM, Canhão P, Stam J, Bousser M-G, Barinagarrementeria F, et al. Predictors of Outcome in Patients With Cerebral Venous Thrombosis and Intracerebral Hemorrhage. Stroke. febrero de 2007;38(2):337-42.

42. Saposnik G, Barinagarrementeria F, Brown RD, Bushnell CD, Cucchiara B, Cushman M, et al. Diagnosis and Management of Cerebral Venous Thrombosis: A Statement for Healthcare Professionals From the American Heart Association/American Stroke Association. Stroke. abril de 2011;42(4):1158-92.

43. Ferro JM, Coutinho JM, Dentali F, Kobayashi A, Alasheev A, Canhão P, et al. Safety and Efficacy of Dabigatran Etexilate vs Dose-Adjusted Warfarin in Patients With Cerebral Venous Thrombosis: A Randomized Clinical Trial. JAMA Neurol. el 1 de diciembre de 2019;76(12):1457. 
Figures

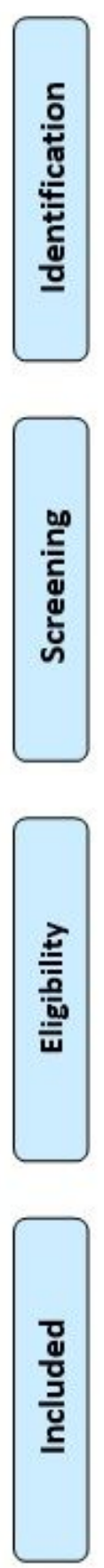

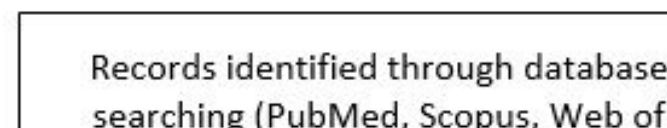
searching (PubMed, Scopus, Web of Science, OpenGrey and Wiley) ( $n=1535)$
Additional records identified through other sources (Snowballing method)

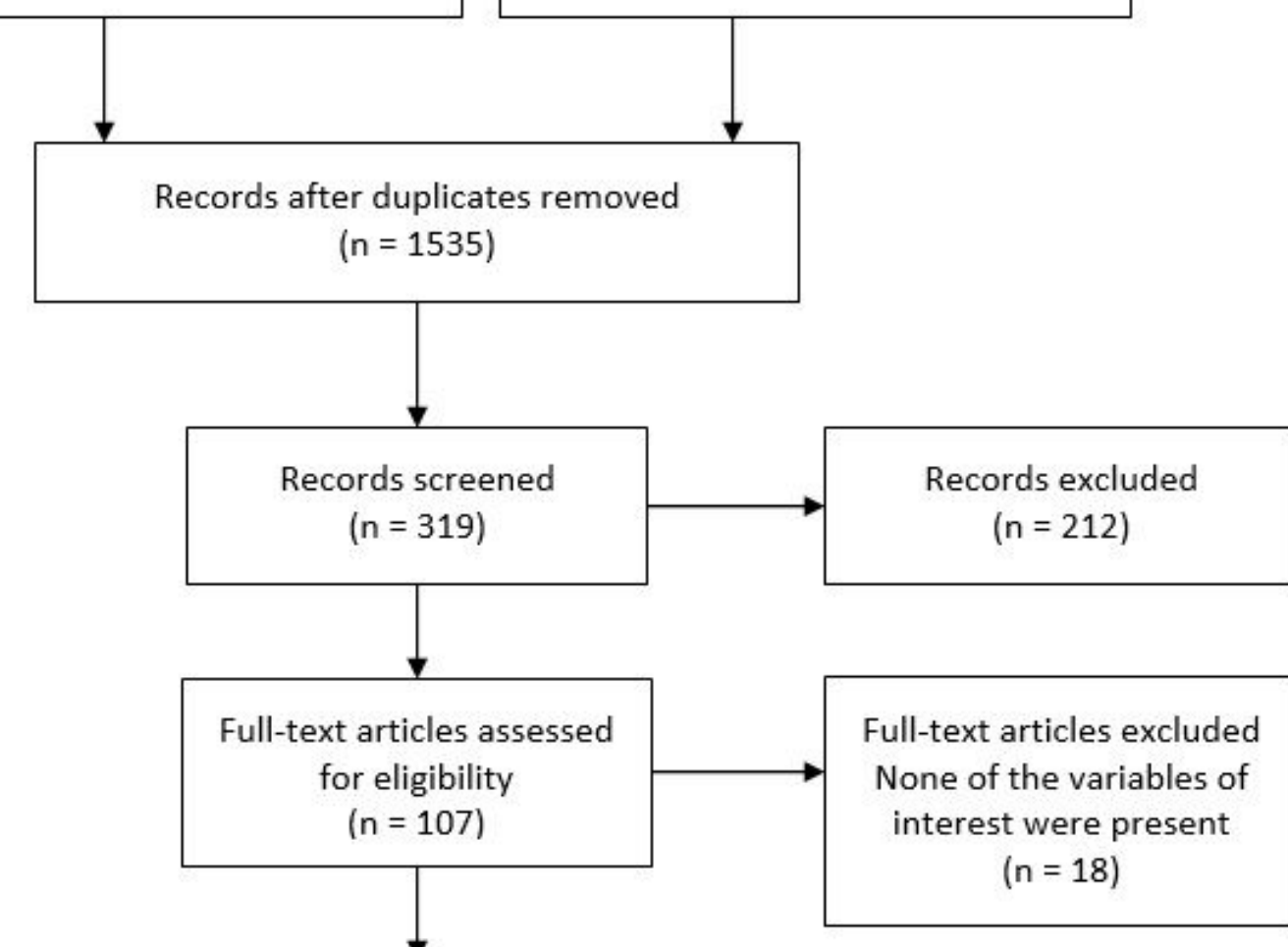

Studies included in qualitative synthesis

$$
(n=89)
$$

\section{Figure 1}

PRISMA Flow Diagram

\section{Supplementary Files}

This is a list of supplementary files associated with this preprint. Click to download. 
- eAppendix.docx

Page 24/24 